\title{
EDITORIAL
}

\section{Eppur si muove, or COPD treatment success and inflammation}

\author{
J.B. Soriano* and N.C. Barnes ${ }^{\#}$
}

I $\mathrm{t}$ has been said that if science was to be given a start date, it should be 1632, when the Italian astronomer and physicist, Galileo Galilei, published the Dialogue Concerning the Two Chief World Systems [1]. Galileo studied the heavens systematically and, in December 1610, used his telescope to show that Venus went through phases, just like the Moon. This observation was incompatible with the Ptolemaic system, the geocentric view that persisted for at least 2,000 yrs, which stated that the Earth was the centre of the Universe. Galileo provided the crucial observations that proved the Copernican heliocentric hypothesis. His work and his actions helped to set up what we now call science. Galileo uttered the landmark phrase "Eppur si muove" meaning "And yet it moves," after being forced to recant in 1633 before the inquisition of his book and of his belief that the Earth moved around the Sun.

In the current issue of the European Respiratory Journal, POWRIE et al. [2] report on a well-conducted, 1-yr clinical trial of tiotropium in chronic obstructive pulmonary disease (COPD). The trial confirms results of previous studies showing that tiotropium reduces exacerbations and improves lung function and symptoms [3]. However, the trial also examines mechanisms, with the primary end-point being a measure of the potential anti-inflammatory effects of tiotropium. To the surprise of the investigators, the observed clinical benefits were associated with increases in several sputum (interleukin (IL)-6 and myeloperoxidase) and serum (IL-6 and C-reactive protein (CRP)) inflammatory markers in individuals exposed to tiotropium. Most surprisingly, there was a statistically significant, and probably biologically relevant, increase in sputum IL-8. Both IL-6 and IL-8 are considered important inflammatory markers in COPD, with some of the evidence coming from earlier research by the same group [4,5]. POWRIE et al. [2] reasonably conclude that the beneficial clinical effects of tiotropium treatment in COPD cannot be attributed to inflammatory modulation. Their a priori sample size calculation of 170 patients (85 patients in each group) aimed to detect, with $80 \%$ power, a $25 \%$ reduction in sputum IL-6

\footnotetext{
*Program of Epidemiology and Clinical Research, CIMERA, Bunyola, Spain. \#Dept of Respiratory Medicine, London Chest Hospital, London, UK.
}

STATEMENT OF INTEREST: None declared.

CORRESPONDENCE: J.B. Soriano, Program of Epidemiology and Clinical Research, CIMERA, Recinte Hospital Joan March, Carretera Soller Km 12, 07110 Bunyola, Spain. Fax: 34971148442 E-mail: jbsoriano@caubet-cimera.es from $165 \mathrm{pg} \cdot \mathrm{L}^{-1}$ to $123 \mathrm{pg} \cdot \mathrm{L}^{-1}$. In 142 randomised participants, POWRIE et al. [2] measured an increase of IL-6 area under the curve from 4,198 week $\cdot \mathrm{pg} \cdot \mathrm{mL}^{-1}$ in placebo to 4,898 week $\cdot \mathrm{pg} \cdot \mathrm{mL}^{-1}$ in tiotropium, which is a stunning $17 \%$ increase in tiotropium versus placebo. What is the cause of this increase? Methodology seems sound, eppur si muove. The trial has elegance and merit but some limitations are worth discussing. Regrettably, due to a technical problem with the induced sputum samples it was not possible to analyse cells, which precludes any data on the behaviour of neutrophils, macrophages and other cells in sputum. All statistics were based on the intention-to-treat population, but at the end of the trial about a third of participants were unable to produce sputum samples, and CRP serum change (0-12 months) was only available for half of the sample. Approximately $75 \%$ of patients in the trial were taking inhaled steroids and this represents a possible confounding factor as remarked upon in the article. The absence of a modifying effect observed in COPD patients, either naïve or users of inhaled steroids at baseline, is challenging. Participants were from the East London (UK) COPD cohort, perhaps one of the better-studied and best-managed groups of COPD patients worldwide. Are they truly representative? An important methodological issue is how exacerbations of COPD were assessed. They were defined symptomatically as the presence for $\geqslant 2$ consecutive days of increase in any two "major" symptoms (dyspnoea, sputum purulence, sputum volume) or increase in one major and one "minor" symptom (wheeze, sore throat, cough, symptoms of a common cold). This symptom-based definition of COPD exacerbation is one that has been used previously by the authors' group, but is rarely utilised in other studies, which more conventionally use healthcare utilisation, either with present need for antibiotics, oral steroids or both. The frequency of COPD exacerbations treated with antibiotics or steroids, or requiring use of emergency care or admission to hospital was too small to compare with other cohorts. The advantages and limitations of using symptom-based rather than health services-based definitions of COPD exacerbation have been recently reviewed [6], where it was suggested that a minimal clinically important difference (MCID) is a $22 \%$ difference from baseline or one event per year for the latter. An MCID for symptom-based COPD exacerbations is not yet available.

The late Sir Karl Popper, considered by many to be the most important contemporary philosopher of science, indicated that modern science advances by rejecting ill-conceived hypotheses and formulating new ones. The search for anti-inflammatory 
effects of COPD medications is elusive. It has been difficult to show that inhaled steroids have anti-inflammatory properties, although two recent studies have shown the combination of an inhaled steroid and a long-acting $\beta_{2}$-agonist does have antiinflammatory properties, and it is thought that this may be part of the mechanism by which these drugs work [7, 8]. However, the study by POWRIE et al. [2] demonstrates that a drug can be an effective treatment for COPD without having anti-inflammatory properties, and that beneficial effects on lung function and symptoms occurred with increases on underlying inflammation. A reduction in exacerbations could occur without an effect on inflammation if the bronchodilator prevented the individual crossing of the threshold on which a given reduction in lung function was detected. Effects of tiotropium beyond bronchodilation, including reduction of mucus hypersecretion, lower airway bacterial colonisation or even lung remodelling, have been discussed elsewhere [9]. However, it is more difficult to explain how a bronchodilator alone could reduce mortality or lower the rate of decline of forced expiratory volume in one second (FEV1) over time. Recent analysis of the TOwards a Revolution in COPD Health (TORCH) data indicates that combination therapy can reduce the rate of decline of FEV1 in COPD [10], whilst there was a strong trend towards a reduction in mortality [11].

Three centuries after Galileo, Sir Austin Bradford Hill reported nine considerations for causation [12]; criterion six is plausibility, which indicates that "an event should agree with the currently accepted understanding of pathological processes." However, studies that disagree with established understanding of biological processes may force a re-evaluation of accepted beliefs. That chronic obstructive pulmonary disease is an inflammatory disease is underlined by guidelines [13]. Therefore, treatments that work should reduce and not increase the inflammatory burst associated with chronic obstructive pulmonary disease; perhaps only in theory. The importance of inflammation in chronic obstructive pulmonary disease will be enormously increased when the results of the Understanding the Potential Long-term Impacts on Function with Tiotropium (UPLIFT) study are published in 2008, as the study's primary outcome variable is rate of decline of forced expiratory volume in one second. The UPLIFT study might have enough power to determine whether there is also a reduction in mortality.

\section{REFERENCES}

1 Galilei G, ed. Dialogue Concerning the Two Chief World Systems, Ptolemaic and Copernican (Unknown Binding). Berkeley, University of California Press, 1953.

2 Powrie DJ, Wilkinson TMA, Donaldson GC, et al. Effect of tiotropium on sputum and serum inflammatory markers and exacerbations in COPD. Eur Respir J 2007; 30: 472-478.

3 Barr RG, Bourbeau J, Camargo CA, Ram FS. Tiotropium for stable chronic obstructive pulmonary disease: a metaanalysis. Thorax 2006; 61: 854-862.

4 Donaldson GC, Seemungal TA, Patel IS, et al. Airway and systemic inflammation and decline in lung function in patients with COPD. Chest 2005; 128: 1995-2004.

5 Perera WR, Hurst JR, Wilkinson TM, et al. Inflammatory changes, recovery and recurrence at COPD exacerbation. Eur Respir J 2007; 29: 527-534.

6 Calverley PM. Minimal clinically important difference exacerbations of COPD. COPD 2005; 2: 143-148.

7 Barnes NC, Qiu YS, Pavord ID, et al. Antiinflammatory effects of salmeterol/fluticasone propionate in chronic obstructive lung disease. Am J Respir Crit Care Med 2006; 173: 736-743.

8 Bourbeau J, Christodoulopoulos P, Maltais F, Yamauchi Y, Olivenstein R, Hamid Q. Effect of salmeterol/fluticasone propionate on airway inflammation in COPD: a randomized controlled trial. Thorax 2007; [Epub ahead of print PMID: 17557771].

9 Barnes PJ. The role of anticholinergics in chronic obstructive pulmonary disease. Am J Med 2004; 117: Suppl. 12A, 24S-32S.

10 Celli B, Ferguson GT, Anderson JA, et al. Salmeterol/ fluticasone propionate (SFC) improves lung function decline and reduces the rate of decline over three years in the TORCH Survival Study. Am J Respir Crit Care Med 2007; 175: A763.

11 Calverley PM, Anderson JA, Celli B, et al. Salmeterol and fluticasone propionate and survival in chronic obstructive pulmonary disease. N Engl J Med 2007; 356: 775-789.

12 Hill $\mathrm{AB}$. The environment and disease: association or causation? Proc $R$ Soc Med 1965; 58: 295-300.

13 Celli BR, MacNee W, ATS/ERS Task Force. Standards for the diagnosis and treatment of patients with COPD: a summary of the ATS/ERS position paper. Eur Respir J 2004; 23: 932-946. 